\title{
Activismo estético afrodescendiente en Colombia: emociones y desplazamiento en videoblogs de Youtube
}

Resumen: Este artículo analiza los emotives (cf. Reddy 2001: 128) expresados en los vlogs de Cirle Tatis y Yudis Rivas a partir del análisis multimodal del discurso (cf. Kress 2010, 2012). En primer lugar, se contextualiza al grupo demográfico afrocolombiano al que pertenecen las vloggers en la historia y el presente del país. En segundo lugar, se reflexiona sobre la importancia de las redes sociales y de las funciones pos-masivas tras el advenimiento de la Web 2.0 (cf. Lemos 2010: 417). En tercer lugar, se hace un close reading de los vídeos, centrando el análisis en el papel de la procesualidad en la expresión de las emociones para la articulación del orgullo del pelo afro y de la identidad negra (cf. Segato 2010), prestando especial atención a la representación de la vulnerabilidad (cf. Butler / Gambetti / Sabsay 2016).

Palabras clave: afrodescendencia, Colombia, Youtube, activismo estético, vulnerabilidad

En los últimos años de la segunda década del siglo XXI, Colombia se ha situado con alrededor de ocho millones como el segundo país del mundo, detrás de Siria, en número de desplazamientos forzados a causa del (post-)conflicto armado que asola al país desde el siglo pasado (cf. ACNUR 2019: 6). Los afrodescendientes se han visto afectados con especial virulencia por este fenómeno. AFRODES, la Asociación de Afrocolombianos Desplazados, calcula que solo en 2018 unos 35.000 desplazados -como se denomina en sentido peyorativo a los afrodescendientes que se vieron forzados a migrar por el conflicto- tuvieron que dejar sus casas para evitar su muerte y buscar suerte en las grandes ciudades del país (cf. Rodríguez 2018). Estos afrocolombianos afrontan en sus nuevos destinos un segundo desplazamiento, de tipo social, en tanto que se les discrimina por el color de su piel, pero también porque se criminaliza la pobreza que se supone -y que en muchos casos- conlleva su proceso migratorio. No obstante, esta discriminación y los discursos que la sustentan tienen profundas

Danae Gallo González, Justus-Liebig-Universität Gießen

Ә Open Access. ( 2021 Danae Gallo González, published by De Gruyter. (cc)BY This work is licensed under the Creative Commons Attribution 4.0 International License. 
raíces históricas ancladas en la diáspora africana que originó la trata de esclavos. Por este motivo, muchos afrodescendientes que no se han tenido que desplazar por el conflicto o cualquier otro motivo se ven subsumidos metonímicamente en el discurso peyorativo sobre el "otro-desplazado" "negro", "pobre” y, en consecuencia, potencialmente criminal. De este modo, la rica variabilidad de experiencias afrodescendientes en Colombia queda invisibilizada y, por ende, múltiplemente desplazada.

Siguiendo el enfoque de este volumen en la cascada de emociones que desencadena todo tipo de desplazamiento -sea este literal, es decir, migratorio, o metafórico, es decir, político-social- este artículo se propone analizar la articulación de las emociones, los emotives, ${ }^{1}$ que expresan los afrocolombianos en una de las redes sociales de mayor impacto en la actualidad en este país. Se examinarán los vídeos de inicio de los vlogs de Youtube de dos activistas estéticas afrocolombianas: Cirle Tatis y Yudis Rivas. En primer lugar, se contextualizará el grupo demográfico afrodescendiente en la historia y el presente colombiano, marcado por su llegada a la actual Colombia con la trata de esclavos y por las consecuencias de esta hasta el día de hoy por las que sigue siendo un desplazado en la sociedad actual. Después, se reflexionará sobre el rol de las redes sociales y las funciones pos-masivas (cf. Lemos 2010: 417) tras el advenimiento de la Web 2.0 y sobre cómo estas facilitan la expresión y la cohesión grupal de grupos minorizados. ${ }^{2}$ A continuación, se examinará el papel de la procesualidad y el estatismo en la expresión de las emociones, en especial, del orgullo de la identidad racial, entendida esta en su vertiente contructivista como signo (cf. Segato 2010: 137). Por último, se analizará el entendimiento y reconocimiento de la vulnerabilidad (cf. Butler / Gambetti / Sabsay 2016b) en la articulación del orgullo que se lleva a cabo en los vlogs.

\footnotetext{
1 Los emotives son un tipo de acto de habla que se distingue de los actos de habla performativos y constativos en tanto que reúne las funciones de ambos, es decir, describe y crea una realidad. Toda expresión de una emoción tiene una intención relacional y un efecto transformador y en ocasiones impredecible en el dispositivo emocional de los implicados en el proceso comunicativo (cf. Reddy 2001: 128).

2 En este artículo, minorizado o minorizada se utiliza como adjetivo o sustantivo en lugar de minoritaria o minoría para enfatizar que ese grupo ha sido constituido discursivamente como una minoría, pero que esta designación oculta el hecho de que en las ciencias sociales y a menudo en la política y/o en el lenguaje coloquial, la designación de un grupo como minoritario no se debe a criterios cuantitativos (p. ej., a las mujeres se las denomina a menudo minoría, pero cuantitativamente no lo son). Con este término se enfatiza que el uso acrítico de la palabra minoría crea la ficción de que cierto grupo constituye una verdadera minoría numérica, lo que contribuye, a su vez, a su deslegitimación (cf. Ferreira 2006: 82).
} 


\section{Los afrodescendientes en Colombia y su puesta en escena en Youtube}

La historia de los afrodescendientes en Colombia está marcada por el desplazamiento: los primeros africanos llegaron forzados al país en el siglo XVI con la llamada globalización ibérica (cf. Gruzinski 2004: 15) y el subsiguiente comercio transatlántico de esclavos que se extendió hasta comienzos del siglo XIX (cf. Urrea Giraldo / Rodríguez Sánchez 2016: 33). Lo hicieron en condiciones existenciales execrables, justificadas por diferentes lógicas discursivas racializantes y racistas a lo largo del tiempo que fundaron las bases de su inclusión excluyente en la configuración del Estado-Nación moderno colombiano tras su independencia de España en 1821. Las élites criollas se adueñaron de las teorías del racismo científico y su defensa de una jerarquía racial de tipo biológico-moral para promover la homogeneidad de la nación a través de la negación y de la reducción del componente africano de la población (cf. Góngora Mera / Vera Santos / Costa 2019: 206). La segregación geográfica de los afrodescendientes hacia la periferia fue en Colombia el método principal de homogeneización racial que conformó lo que Peter Wade denomina la "geografía moral racializada de la nación” (Wade 1997: 86). A pesar de la abolición oficial de la esclavitud en $1851^{3}$ y de la adaptación del discurso racializante en torno a lo "mestizo" tras el desprestigio del racismo científico "post-1945" (Góngora Mera / Vera Santos / Costa 2019: 34), ciertas regiones del país se imaginan hasta el día de hoy como más o menos negras y, por lo tanto, más o menos civilizadas siguiendo la lógica del viejo discurso eurocéntrico de la civilización / barbarie (cf. Zapata Cortés 2018: 25; Restrepo 2013: 51).

Desde los noventa del siglo pasado, pero sobre todo en las últimas décadas, los gobiernos colombianos han tomado medidas destinadas a reconocer esta violencia histórica y sus consecuencias hasta el día de hoy (cf. Wade 1997: 47). Además, con estas medidas se pretende hacer frente a la discriminación que sufren y han sufrido los afrodescendientes durante el conflicto armado. La Constitución colombiana de 1991 otorgó reconocimiento a los derechos de las comunidades negras en sus territorios y su autonomía cultural. En 2011, el Decreto Ley 4635 de 9 de diciembre se comprometió a prestar asistencia a los afrodescendientes, víctimas del conflicto armado. Muchos se habían visto obligados a migrar hacia el interior del país y las tierras, que les pertenecían en virtud a la Constitución de

3 Cuevas proporciona un matizado análisis histórico del proceso abolicionista en la Nueva Granada, actual Colombia, antes y después de la independencia del país de España (cf. Cuevas 2018). 
1999, les habían sido expropiadas. Uno de los preceptos del Decreto Ley de 2011 estipulaba la restitución de tierras usurpadas a los afrodescendientes en este contexto. En paralelo con esta intervención estatal, el activismo afrodescendiente ha ido cobrando fuerza desde principios del siglo XXI en Colombia y en toda Sudamérica, sobre todo a partir de la celebración de la Conferencia Mundial contra el Racismo, la Discriminación Racial, la Xenofobia y las Formas Conexas de Intolerancia en Durbán, Sudáfrica, en 2009 (cf. Lao-Montes 2009: 219). La efectividad de sus esfuerzos queda plasmada con especial claridad en la declaración de la ONU del año 2011 como el Año Internacional de los Afrodescendientes y de la Década Afrodescendiente de 2015 a 2025.

No obstante, este grupo demográfico, a pesar de ser uno de los más extensos del mundo fuera de África después de Estados Unidos, Venezuela y Brasil (cf. Freire et al. 2018: 54), sigue siendo en Colombia un desplazado social. ${ }^{4}$ Este sector de la población es víctima de racismo estructural y tiene uno de los peores indicadores de desigualdad del continente americano, tanto en las tradicionales geografías de la pobreza $a^{5}$ a las que se habían visto relegados gran parte de los afrodescendientes en la periferia del país, como en las grandes ciudades (cf. Lao-Montes 2009: 234; Rincón Becerra 2017: 2289).

Desde el punto de vista académico, el estudio preferente de estas geografías de la pobreza y de la ruralidad en las que se concentran los afrodescendientes, ha fomentado, indirectamente, la invisibilización de numerosos afrodescendientes residentes en otras zonas del país y provenientes de otros contextos sociales. Así, el mundo universitario ha contribuido indirectamente a reproducir discursos estereotipados y simplistas sobre este variado grupo de la población

4 Cf. Montoya Arango / García Sánchez 2010: 45; también Restrepo / Rojas 2004: 22. Las estadísticas no son del todo fiables, puesto que los criterios de clasificación de la población como afrodescendiente varían mucho de un país a otro. El censo colombiano calcula que los afrodescendientes en el país suponen alrededor de un 11\% de la población total, dato que pone en duda el Movimiento Cimarrón Colombiano, que asegura que la cifra debe situarse alrededor del 40\% (cf. Movimiento Cimarrón Colombiano 2017). Por su parte, Urrea Giraldo y Rodríguez Sánchez calcularon en 2004 que los afrocolombianos podrían ser un 18-20\% del total de la población (cf. Urrea Giraldo / Rodríguez Sánchez 2016: 37). Según Urrea Giraldo y Rodríguez Sánchez esta disparidad se debe, entre otros factores, a que solo se registró a los afrodescendientes que se auto-reconocieron como tal en las categorías de la pregunta censal y que un gran sector de la población mestiza no se identificó con dichas categorías (Urrea Giraldo / Rodríguez Sánchez 2016: 38). Movimiento Cimarrón Colombiano advierte de que muchas personas no pudieron acceder a Internet para realizar la encuesta.

5 Expresión con la que, en la disciplina de la Geografía Social, se indica la concentración de la pobreza en áreas geográficas determinadas. Según Agudelo, que se basa en estudios demográficos, la mayoría de las poblaciones negras colombianas habitan en concentraciones urbanas: un 70\% del total (cf. Agudelo 2004: 174). 
de Colombia, a saber: los afrodescendientes colombianos viven en el Pacífico, sobre todo en el Chocó, algunos en el Caribe y, en su mayoría, en contextos rurales y/o precarios (cf. Agudelo 2004: 174; Cunin 2004: 148).

No solo los académicos, sino también los medios de comunicación de masa -jerárquicos, unidireccionales, de alcance nacional y siguiendo una lógica capitalista de mercado (cf. Lemos 2010: 403-404)- han contribuido, en gran parte, tanto a la (re-)producción del racismo manifiesto o latente y del endoracismo ${ }^{6}$ en el país, como a la falta de circulación de voces que luchan por el empoderamiento de los afrodescendientes (cf. Restrepo 2008: 200). En 2004 nació la llamada Web 2.0, que por primera vez incluía funciones en el sistema que permitieron a los usuarios interactuar y colaborar entre sí como creadores de contenido. André Lemos llama a estas funciones lanzadas en la Web 2.0 pos-masivas (cf. Lemos 2010: 417). ${ }^{7}$ Estas no son novedosas en Internet, porque ya existían desde hace tiempo en los medios de comunicación análogos, como los fanzines, folletos y otros medios alternativos. No obstante, según indica Lemos, el lanzamiento de la Web 2.0 supuso un impulso renovado para estas funciones. El autor arguye que en ellas radica la potencialidad de crear un entorno comunicacional más participativo y multidireccional (cf. Lemos 2010: 404). Sin embargo, tampoco debe exagerarse el alcance de la democratización producida por las funciones pos-masivas de Internet: tan solo un 52,7\% de la población colombiana tenía acceso a internet en sus hogares en $2018,{ }^{8}$ no todas las personas tienen el mismo grado de alfabetización digital y las funciones de los medios de comunicación de masas coexisten en el mundo digital con las pos-masivas.

A pesar de estas matizaciones, no es aventurado afirmar que los medios digitales de comunicación en red consiguen romper de manera efectiva con algunas de las trabas que imponían los tradicionales medios de comunicación de masa. Asimismo, los medios pos-masivos hacen que la producción y la circulación del conocimiento pueda llevarse a cabo de manera más equitativa en tanto en cuanto posibilitan un aumento exponencial del número y del perfil de emisores y receptores de contenido (cf. Lemos 2010: 404). De hecho, como muestran estudios recientes, Latinoamérica es la región en la que más se usan las redes sociales, a pesar de tener peor conexión que otros lugares del globo

\footnotetext{
6 Dícese de la internalización de prejuicios racistas y racializantes por parte de personas afrodescendientes.

7 Lemos no usa el prefijo pos para aludir algo que llega al final del proceso de los medios de comunicación de masa, sino para expresar una manera nueva de entender lo que no puede incluirse en la etiqueta de medios de comunicación de masa (cf. Lemos 2010: 417).

8 Cf. DANE 2018: 12. En enero de 2020 no hay datos más actuales.
} 
(cf. Marchant 2018). En consecuencia, puede argüirse que las redes sociales y el espacio digital se convierten en contenedores y medios de producción participativos para la (re-)negociación, disputa y/o contestación de significados sobre la afrodescendencia (cf. Da Moita Lopes 2010: 398; Vergès 2017: 46; Sobande 2017: 657).

En base a todo lo expuesto con anterioridad, este artículo explora la articulación de cómo se siente ser afrodescendiente en Colombia en pleno siglo XXI a partir de lo que comunican sus protagonistas en una de las redes sociales de mayor impacto en la actualidad en este país: Youtube. Según el gerente general de Google en Colombia, Giovanni Stella, el uso de Youtube en 2018 fue muy superior en el país en relación con el resto de Latinoamérica (cf. Stella en: Chiquiza Nonsoque 2018), situándose en 2016 en segundo puesto en el consumo de vídeo online (cf. Navarrete 2016). Bajo la premisa de que esta plataforma produce, almacena y reproduce discursos que articulan y sirven de sostén de identidades colectivas y que tienen una influencia real en la vida de las personas, Youtube se convierte, pues, en un medio privilegiado para examinar la expresión de la cascada de emociones que desencadena vivir en desplazamiento por ser afrocolombiano en la actualidad.

Más específicamente, se examinan dos vídeos de dos de las vloggeras afrocolombianas con más visualizaciones. Los vlogs -videoblogs, es decir weblogs o bitácoras en forma de vídeo en internet- son galerías de vídeos breves, subidos periódicamente por un productor de contenido o vlogger. Estos clips se distribuyen y almacenan gratuitamente a partir de plataformas en línea, mayoritariamente a través de algún canal de Youtube. La creciente estandarización formal y de contenido experimentada por los vlogs hace que puedan tacharse de un verdadero género discursivo. Los vídeos suelen tener una duración media de unos 10 minutos en el mundo hispano (cf. De Piero 2014: 83). Los vloggers se dirigen normalmente en primeros planos frontales directamente a su audiencia a través de deícticos personales. Además, a pesar de la aparente espontaneidad de los clips, estos suelen haber sido planeados, incluso en ocasiones guionizados con un lenguaje que se ha tildado de "escritura oralizada" (Maldonado 2011: 132-133). Asimismo, los vídeos subidos suelen haberse editado a través de rápidos y bruscos “cortes directos" (De Piero 2014: 84), técnica que, por su amplia estandarización internacional, puede considerarse una verdadera marca del género vlog. Temáticamente los vlogs presentan diferentes grados de especialización: algunos se centran en las experiencias diarias del vlogger y, por lo tanto, se asemejan en forma y función a un diario público o publicado. Otros están especializados en una temática de interés para un grupo específico y los vloggers comparten su conocimiento y opinión sobre, por ejemplo, libros, automoción o música. 
En lo que concierne a este artículo, el tema principal de los vlogs es mayoritariamente el cuidado y la estética del pelo afro. Otra característica de este género es que permite la interactividad con otros usuarios por medio de la función de los comentarios y/o de las respuestas cruzadas a través de vídeos. En este caso, el análisis del aparato paratextual y de los comentarios no se incluirá en el análisis porque excede el alcance del artículo. Estos últimos, si bien contribuyen a la producción de un discurso para todo aquel que acceda al vídeo, no forman parte de la intención comunicativa primigenia de las emisoras.

Este artículo se centra en el análisis de los clips de inicio de los vlogs, que, por lo tanto, sirven de carta de presentación de los mismos. ${ }^{9}$ El objetivo es, según el entendimiento del método socio-semiótico y multimodal de Kress (Kress 2010), deducir las semánticas (audio)-visuales que se entraman en estos vídeos alrededor de los emotives (cf. Reddy 2001: 128). Los emotives son un tipo de expresión de las emociones que se distingue de los actos de habla performativos y constativos en tanto que reúne las funciones de ambos, es decir, describe -como los constativos- y crea una realidad -como los performativos-. ${ }^{10}$ Todo emotive tiene una intención relacional y un efecto transformador en el dispositivo emocional por el que navegan todos los implicados en el proceso comunicativo (cf. Reddy 2001: 100-101). Según este autor, los interlocutores navegan entre los efectos -en ocasiones impredecibles- que tiene el acto de expresar una emoción como lo hiciera un barco en alta mar, es decir, sin saber adónde le llevarán las corrientes, si llegará al puerto elegido, si cambiará radicalmente la ruta y/o cómo llegará a su destino (cf. Reddy 2001: 122). En este sentido, este artículo examina cómo se articulan estos emotives en la construcción identitaria en torno a la "raza" que proponen los vídeos. ${ }^{11}$ Se entiende “raza” como signo (cf. Segato 2010: 137), es decir, como una construcción histórica y relacional que depende de, y varía en función de los contextos de interacción social específicos. A partir de estos contextos se dota al significante "raza" de significado. Por lo tanto, este significado es siempre contingente, es decir,

9 No obstante, rompen en cierto sentido con el tenor de los vlogs, que suelen centrarse en dar consejos de cómo cuidar del pelo afro.

10 Nótese que con emotives se amplía el rango de tipo de sistemas semióticos a través de los que se puede transmitir una emoción más allá del lenguaje verbal.

11 Los vídeos se consideran, siguiendo a Kress, entidades semióticas coherentes y completas, integradas, por lo tanto, en lógicas de poder intrínsecas a toda interacción social. Según Kress, estas entidades deben analizarse según las particularidades del medio -en este caso, portador de varios sistemas semióticos (el sonoro y el visual)- con sus particularidades en el modo de construcción de significados que en interacción componen un todo significativo (cf. Kress 2010: 37-39). 
transformable en función del contexto interpretativo en el que se produce y recibe dicho signo.

En este caso, el contexto interpretativo en el que se insertan los vlogs analizados -Pelo bueno y Afro Power- es el de la Colombia de la segunda mitad del siglo XXI en pleno auge de las funciones pos-masivas de la Web 2.0 y la interdependencia de estos factores con la intersección identitaria y situación vital de las protagonistas, que se especifican a continuación. Afro Power lo creó Yudis Rivas el 15 de mayo de 2014. Tiene 77.000 suscripciones y 4.287.545 visualizaciones de media. ${ }^{12}$ Pelo bueno fue creado el 12 de mayo de 2016 por Cirle Tatis. Su cuenta tiene 148.000 suscripciones y 6.464 .505 visualizaciones de media. Yudi Rivas estudia Historia en la Universidad de Antioquía, Medellín. Cirle Tatis es de Cartagena y trabaja en la universidad de su ciudad natal en el Departamento de Comunicación Social. Es decir, ambas tienen o están formalizando estudios superiores y viven en un contexto urbano en Colombia, por lo que representan a un grupo de afrodescendientes poco atendido por el mundo académico, más concentrado, hasta el momento, como se mencionaba con anterioridad, en el estudio de los afrodescendientes provenientes de las geografías de la pobreza. Además, ambas enseñan en sus vídeos trucos de cómo cuidar el pelo y la piel afro y son defensoras del llamado activismo estético.

El activismo estético se concibe, siguiendo la definición propuesta por Shapiro, como todo tipo de práctica que empodere a personas que hayan experimentado deshumanización y que se propongan hacer frente a los efectos resultantes de esta experiencia y reimaginar sus vidas y su identidad, utilizando la estética como arma política (cf. Shapiro 2017: 663). En el contexto de la afrodescendencia, conviene especificar, según la definición de otra activista estética, Desirée Bela-Lobedde, que la práctica del cuidado del pelo, entendida como activismo estético, se convierte en "la lucha [decolonial, no solo de la mente, sino también del cuerpo] contra el canon estético imperante, blanco y eurocentrado" (Bela-Lobedde en: Jurado 2018). Esta lucha, arguye, pone a disposición de las mujeres negras recursos empoderadores "para que aprendan a cuidar de su piel sin aclararla y de su pelo afro natural sin utilizar productos para alisarlo y transformarlo químicamente". ${ }^{13}$

12 Datos del 1 de noviembre de 2019. Los cuatro youtubers más seguidos en Colombia son blancos, el más influyente se llama Ami Rodríguez, con 10 millones de seguidores.

13 Bela-Lobedde (en: Mbomío 2018). Este activismo se inscribe dentro de la cuarta ola del feminismo que reclama explícitamente el derecho a apropiarse la feminidad estereotípica de manera empoderante y de exponerla en las redes sociales a su gusto. A estas últimas, esta modalidad del feminismo las considera plataformas legítimas en las que hacer activismo online (cf. Rivers 2017). 


\section{Pelo bueno: el orgullo rotundo de ser negra}

El vídeo de inicio de Pelo bueno no propone tratamientos capilares, ni contesta a preguntas de sus seguidores, como suele hacerlo la vloggera en la mayoría de sus entradas. Por el contrario, Tatis opta por presentar su canal poniendo en escena lo que podría entenderse como el resultado final de dedicarse al cuidado del pelo afro. En el clip, siete mujeres afrodescendientes declaman por turnos la poesía "Rotundamente negra” (1994) de la costarricense Shirley Campbell Barr. ${ }^{14}$

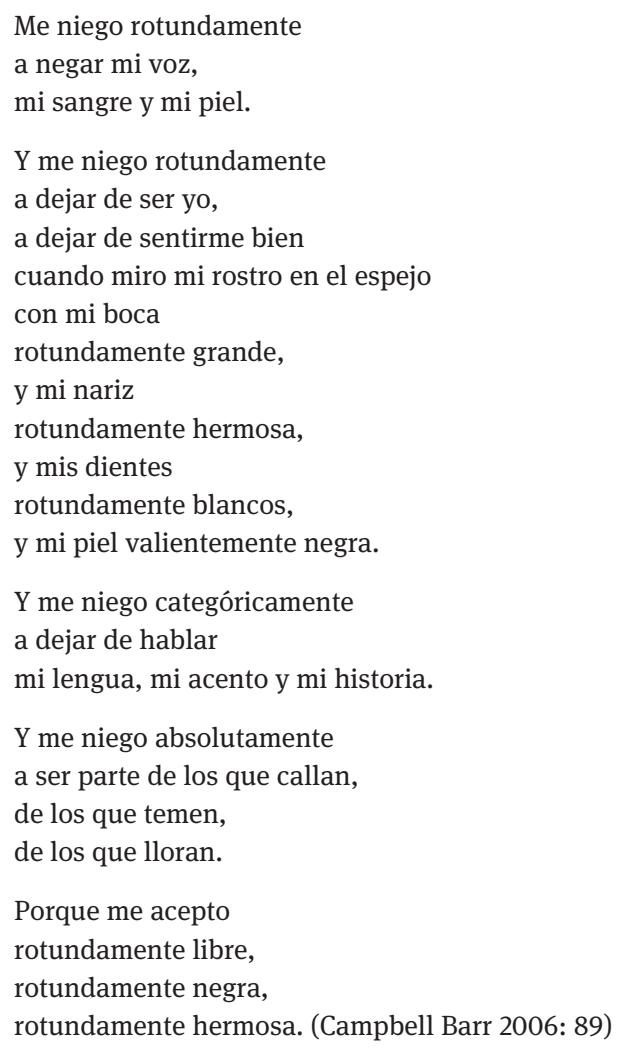

La puesta en escena de la declamación de esta poesía como carta de presentación de su canal pone de manifiesto que la vloggera reconoce la experiencia de Campbell y -para los propósitos de este artículo- las emociones que recoge el poema como propias. El hecho de que la poesía haya sido compuesta por una autora

14 Este poema dio título a una antología de poesía de la autora costarricense (cf. Campbell Barr 2006). 
afrodescendiente pero no oriunda de Colombia no impide que Tatis aplique la experiencia que recoge el texto al contexto colombiano. De esta manera, se apela indirectamente a la transnacionalidad ${ }^{15}$ y diversidad de la experiencia de lo que se constituye en la iteración del acto de habla y en su puesta en escena performativa de la declamación -en el sentido del término de Judith Butler (cf. Butler 1990 y 1996, también 2016) - como una comunidad que se autodenomina “negra”. Los subtítulos en inglés que acompañan al vídeo insisten en el alcance transnacional de la comunidad que quiere transcender las fronteras lingüísticas del castellano a través de esta lingua franca.

Las semánticas visuales refuerzan la articulación poética y estética de una comunidad diversa e inclusiva: la cámara se centra en el rostro de las mujeres a través de primeros planos, mostrando así una variedad de facciones, tonos de piel y estilos de peinado, eso sí, dentro de la estética naturalista. Las transiciones entre planos son limpias o fundidas en negro, sin crear jerarquías entre los planos y, por lo tanto, entre las mujeres. Asimismo, las transiciones tienen lugar al ritmo de la declamación y de los tambores que las acompañan musicalmente. El clip se apropia del sonido de los tambores, utilizados tradicionalmente para representar África, tanto por el negrismo exoticista, como por otros modos de articulación de África como el lugar de "lo primitivo", "lo sensual” o "lo folklórico", como ya hiciera el movimiento de la negritud en los años veinte y treinta del siglo pasado. El montaje de este sonido extradiegético con estas imágenes que enfatizan la diversidad afrodescendiente y que muestran a mujeres declarando diegéticamente la aceptación de su belleza re-semantiza el significado de los tambores y los extirpa del regusto de exotismo racializante. Además, esta semántica acústica sirve para destacar el origen común de la comunidad afro en África dentro de una tradición intelectual propia. La diversidad y la riqueza del legado cultural de los antepasados a los que aluden con los términos "sangre” (Tatis 2016: 0:16) e "historia” (Tatis 2016: 0:51) también se integran, de manera efectiva, sin que haga cuestionar la cohesión del grupo. La unidad de la experiencia se transmite también a través de dos estrategias más: la superposición, en un primer plano, de los rostros de dos mujeres (Ilustración 1. Tatis 2016: 0:13) y el cierre del vídeo con tres planos generales, en los que declaman en coro que se aceptan como mujer "rotundamente libre, rotundamente negra, rotundamente hermosa"16 (Ilustración 2. Tatis 2016: 1:04-1:14).

15 Eso sí, esta transnacionalidad se enmarca dentro de un contexto latinoamericano y caribeño hispanohablante.

16 En los planos generales se puede ver la gran variedad en la vestimenta y el estilo de las mujeres, lo que corrobora la diversidad y riqueza de la expresión de la afrodescendencia. 


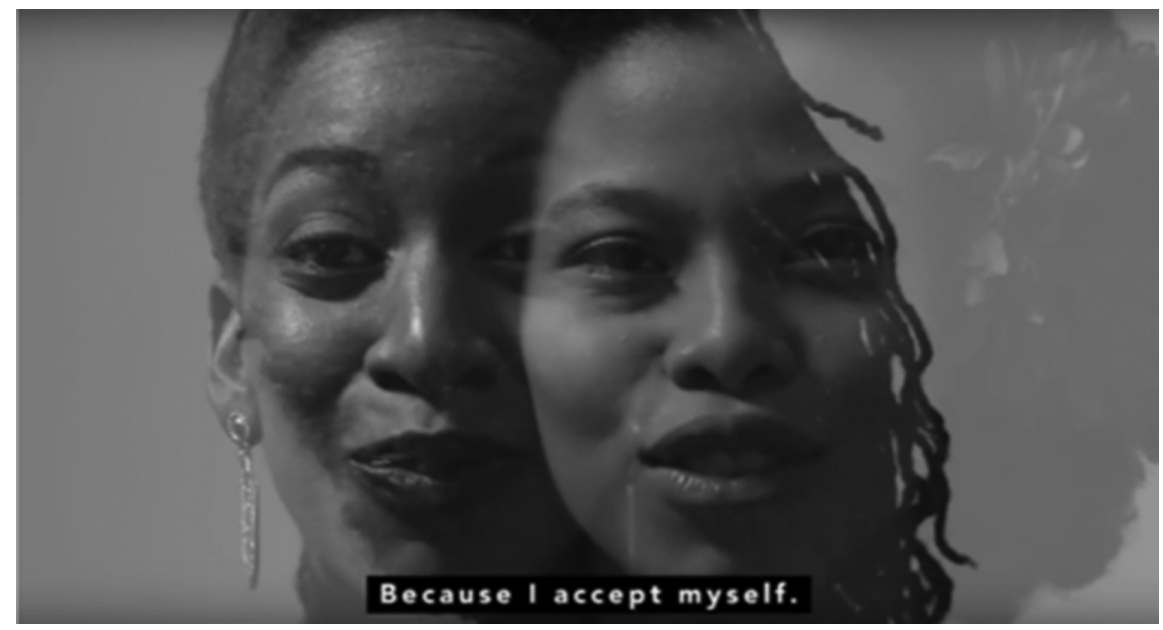

Ilustración 1: Unidad de la experiencia afrodescendiente, primer plano. (Tatis 2016: 1:03)

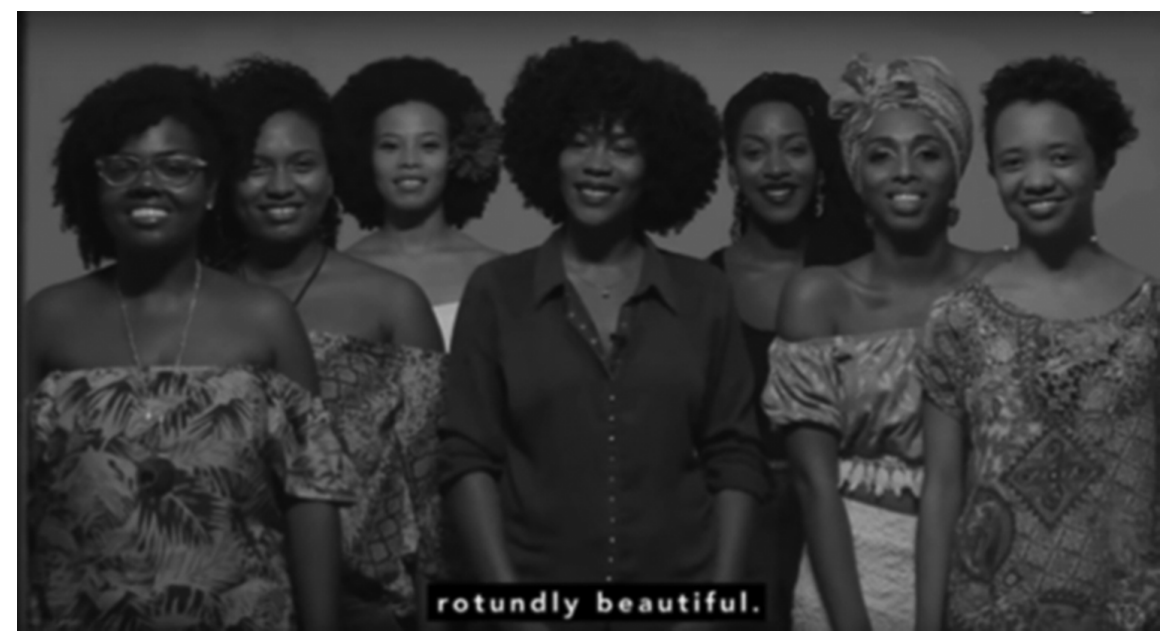

Ilustración 2: Unidad de la experiencia afrodescendiente, plano general. (Tatis 2016: 1:14)

Solo hay una referencia explícita al dispositivo emocional en el mensaje verbal. Este se expresa en los siguientes términos: "Me niego rotundamente a dejar de ser yo, a dejar de sentirme bien cuando miro mi rostro en el espejo con mi boca, rotundamente grande, y mi nariz, rotundamente hermosa, y mis dientes, rotundamente blancos" (Tatis 2016: 0:19-0:39. La cursiva es de la autora). La poesía se refiere así a la sensación del bienestar y a la autoestima con que 
las emisoras afirman relacionarse con su fisionomía "negra". Esta, denostada por el discurso racializante de herencia colonial, se re-semantiza al acompañarla de adjetivos positivos con los que se cierra la declamación -"libre", "hermosa” (Tatis 2016: 1:04-1:14)-, que, a su vez, se modifican a través del adverbio "rotundamente". Además, a través de este adverbio se presenta el grado en el que puede comprenderse la cualidad expresada por los adjetivos. Este adverbio, en su acepción de "sin lugar a dudas" o "de manera definitiva" impone una interpretación única y definitiva de la boca, la nariz, los dientes y la piel, que se tachan de bellos y, en un giro personificador, de valientes. Asimismo, la repetición de la perífrasis terminativa "dejar de" implica que la voz lírica ya se ha instalado en el bienestar e indirectamente en la emoción del orgullo sobre su cuerpo, en contraposición "de los que callan, de los que temen, de los que lloran” (Tatis 2016: 0:57-1:01), es decir, de los que se podrían calificar de vulnerables. El carácter exclusivo de la identidad común reclamada que permea este verso se examinará más adelante. La construcción sintáctica sugiere también una clasificación de los afrodescendientes en función de sus emociones: los orgullosos -que levantan la voz ante su racialización- y los vulnerables -que callan y lloran- y marca un claro distanciamiento de la voz poética frente al segundo grupo.

Todo lo anteriormente analizado, así como aspectos kinésicos, como la sonrisa confiada, la expresión facial relajada y la cadencia de la entonación con la que las protagonistas pronuncian la última frase "rotundamente hermosa" (Tatis 2016: 1:14), hacen que el clip rezume una clara emoción mayoritaria: el orgullo de la belleza. No obstante, un análisis más pormenorizado tanto de la quinesia, como del distanciamiento del yo lírico de los "vulnerables" revela parte del proceso silenciado y las emociones intrincadas en este hasta llegar a la afirmación del orgullo, hasta ese momento emocional que se niega a dejar. Tanto el tono y la entonación, como la expresión facial distan de ser en todo momento afables, desenfadados y/o sonrientes. Los rasgos se endurecen y el tono se eleva al expresar "me niego rotundamente o absolutamente" (Tatis 2016: 0:20) y los rostros se vuelven serios al hablar de los vulnerables, que muestran su temor a través del silencio y del llanto (Ilustración 3, 4 y 5).

El hecho de afirmar que uno se niega a algo expresa oposición y/o antagonismo de algún tipo en relación al cual se constituye una identidad, en este caso "negra”. Nótese que la categoría "negra" se convierte en la puesta en escena realizada por el vídeo en un acto performativo identitario subversivo y político. El uso del significante "negra" se re-significa, así, según el entendimiento de la "raza" como signo (cf. Segato 2010: 137), como hiperónimo inclusivo en cuanto al tono de la piel y de la variedad de experiencias afrodescendientes que integra. 


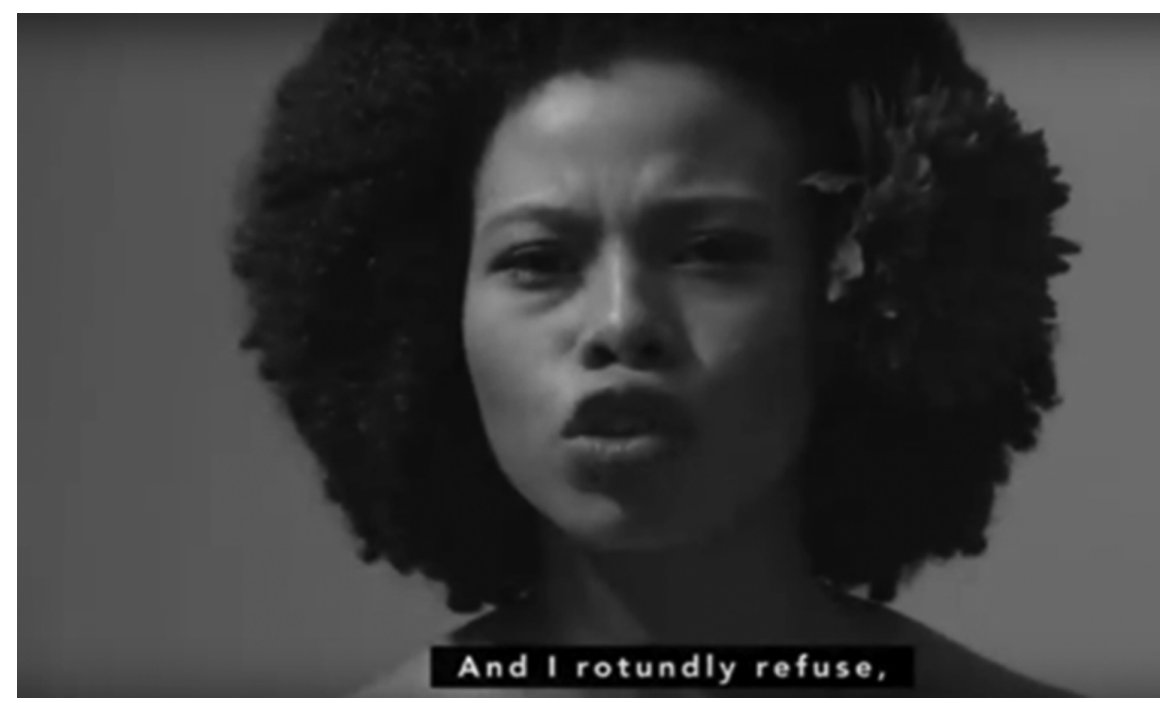

Ilustración 3: Quinesia endurecida 1. (Tatis 2016: 0:58)

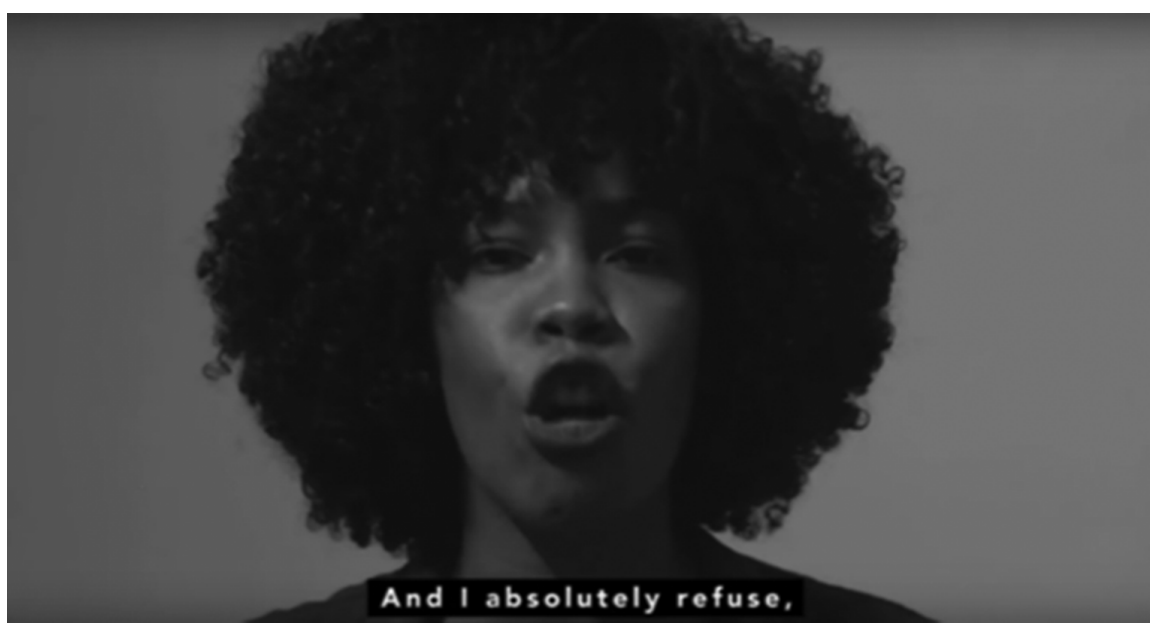

Ilustración 4: Quinesia endurecida 2. (Tatis 2016: 0:19)

No obstante, es necesario resaltar también el carácter exclusivo de la identidad reclamada, e insistir en quién constituye el otro al que se opone y en relación al cual constituye su identidad. Este otro no es solo la sociedad blanca a la que se refiere implícitamente en el poema, si no, como expresa explícitamente, a los que "no luchan, que temen y que lloran" (Tatis 2016: 0:57-1:01). Con estos 


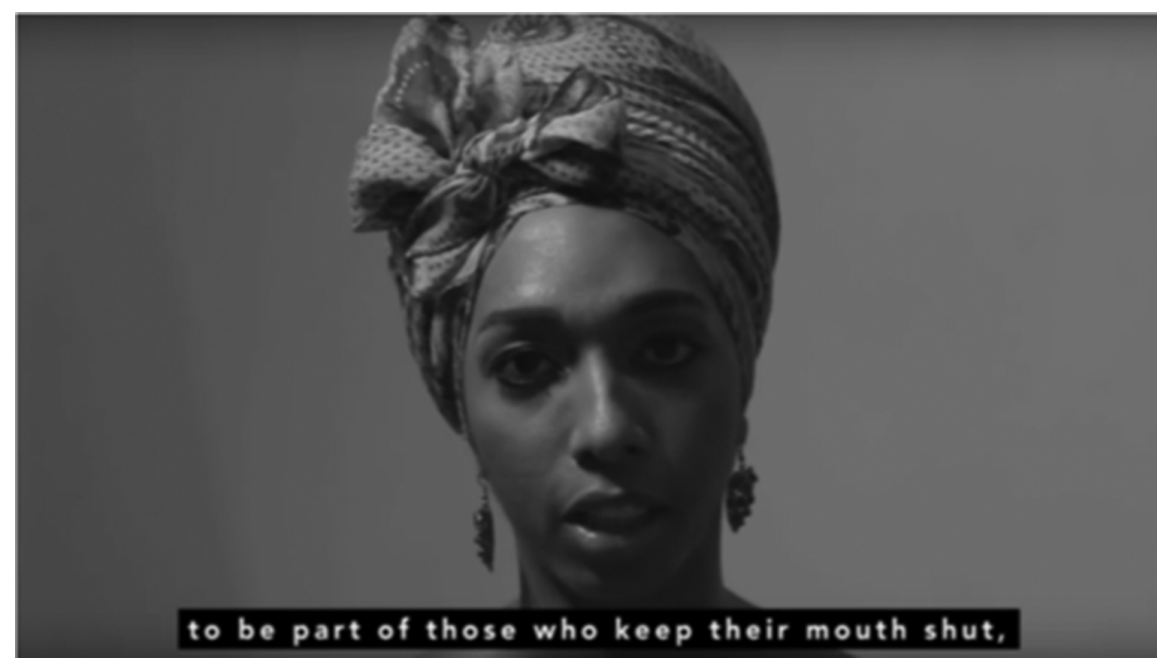

Ilustración 5: Quinesia endurecida 3. (Tatis 2016: 0:58)

el vídeo se refiere a los afrodescendientes que no se oponen a la sociedad blanqueada, ${ }^{17}$ independientemente del color de la piel de sus integrantes, a los que asumen imposiciones epistémicas racializantes sin enfrentarse a ellas. Por ello, afirma explícitamente que se opone a formar parte de los afrodescendientes blanqueados que se instalan o que todavía no han salido de su vulnerabilidad. Se entiende, por lo tanto, la vulnerabilidad como antónimo de la valentía resistente a la racialización de la fisionomía afrodescendiente en la que se sitúa el yo poético, e indirectamente Tatis como activista estética. En el poema, los vulnerables se caracterizan por mostrarse pasivos -callando ante una injusticia por temor ante las consecuencias-, y por expresar este mismo temor, considerado como cobarde, a través de las lágrimas. Así pues, la vulnerabilidad queda articulada en este clip y, por tratarse del vídeo de inicio, en la carta de presentación

17 Se entiende blanqueada y blanqueamiento según el entendimiento de los términos de Wade: “[u]na versión racista de las ideologías de mestizaje en la construcción de nación, que buscaba atraer a inmigrantes europeos para 'mejorar' la población nacional [...] y como proceso individual de movilidad ascendente mediante el cual las personas se distancian de la negridad (y la indigeneidad) cambiando su comportamiento y medio social y quizás hallando una esposa de piel más clara [...] -proceso que podría, o no, estar motivado por un deseo de escapar a la negridad" (Wade 2017: 34). Nótese que el blanqueamiento se ha desarrollado con diferentes matices estéticos, políticos y sociales en distintos países latinoamericanos. No obstante, un estudio pormenorizado del mismo excede el alcance de este artículo. 
del vlog de Pelo bueno, como sinónimo de la victimización, la pasividad, la falta de agencia o, en palabras de Butler, Gambetti y Sabsay, "the site of inaction" (Butler / Gambetti / Sabsay 2016b: 1). Además, el vídeo de Pelo bueno muestra a los visitantes lo que podría entenderse como el resultado final de la puesta en práctica del cuidado del cuerpo: el emotive del orgullo. No obstante, al centrarse en mostrar el resultado final silencia, a su vez, el proceso emocional y las aguas de la vulnerabilidad por las que se navega, siguiendo la metáfora de Reddy (cf. Reddy 2001: 122), hasta llegar a dicha emoción.

\section{Afro Power: navegando hacia el orgullo del pelo natural}

Afro Power también opta por darse a conocer con un vídeo diferente de lo que suele verse en su canal y presentar una narrativa coming of age hacia el pelo natural. La primera escena del vídeo se encarga de narrar las diferentes etapas del proceso emocional por las que pasa la protagonista hasta llegar al punto de inflexión que le lleva a abrazar el afro como expresión de su activismo estético. Los elementos compositivos básicos de esta primera escena del vídeo son los sonidos regulares de los latidos de corazón y la luz tenue, iluminando brevemente y de forma cíclica un rostro de mujer con el pelo recogido, mostrado en primer o primerísimo plano. Estos elementos audiovisuales, usados convencionalmente en películas de ciencia ficción, cuando un personaje renace o despierta de un experimento, invitan a interpretar el vídeo siguiendo un modo de lectura propio a ese contexto interpretativo y anticipan la semántica de renacimiento identitario que propone el clip.

El pronombre temporal cuando, expresado por la voz en off de Rivas que acompaña todo el clip, marca el inicio de cada etapa. La primera se sitúa en la infancia: "Cuando eres niña, no te das cuenta que [sic] eres diferente, que existe una historia [...] que el presente es la historia” (Rivas 2017: 0:06-0:14). Según la voz en off femenina, en la niñez, el sujeto afrodescendiente no se da cuenta de su diferencia respecto a la sociedad mayoritaria, ni del origen discursivo creador de la misma, sostén ideológico de las condiciones existenciales de las personas africanas y afrodescendientes a lo largo de la historia americana. Este origen discursivo de la diferencia queda condensado en el clip en el significante "la historia". Se arguye que el sujeto infantil no es consciente de esta historia, ni de la actualidad de dicha historia en la vida de los afrodescendientes: "el presente es la historia” (Rivas 2017: 0:14). La ignorancia cándida con la que se representa esta etapa se refuerza visualmente al plasmar a la protagonista con los ojos cerrados, pero con una expresión facial relajada (Ilustración 6). 
Ilustración 6: Primera etapa (Rivas 2017: 0:04).

Un fundido en negro sirve de transición a la segunda etapa, en la que surge su imagen con los ojos abiertos, metáfora visual de lo que la voz en off expresa: "cuando te das cuenta que [sic] estás atrapada, que las cadenas te detienen, que no te reconoces, no eres un ser humano. No eres tú, eres ellos” (Ilustración 7. Rivas 2017: 0:18-0:27). La protagonista afirma captar, en un segundo momento, que había estado alienada emocionalmente en su etapa anterior de ignorancia y que ahora es capaz de sentirse agobiada por estar encajonada. Afirma sentirse

Ilustración 7: Segunda etapa (Rivas 2017: 0:23). 
“detenida" dentro de los cánones de la sociedad mayorizada blanqueada, en el ellos, pronombre con el que al mismo tiempo anticipa de nuevo la alteridad que le servirá para formar su yo tras el proceso de renacimiento identitario. Asimismo, el uso de la metáfora de las "cadenas" sirve, no solo para mostrar su estado emocional en esta etapa, sino para insertarlo en una especie de historia de la emoción común al colectivo afrodescendiente con su origen en la esclavitud.

En una tercera etapa, el agobio se torna en angustia, la cámara se acerca y se centra, en un primer primerísimo plano, en los ojos -que se mueven nerviosos- y en la frente, que termina por fruncir el ceño (Ilustración 8). El ritmo de los latidos del corazón y de la voz en off se acelera, al reconocer la rabia y el dolor de "cuando por fin te enteras que [sic] te niegan, que no existes, que no eres, que no puedes ser, gritas, gritas tan fuerte y lloras, te sacudes, te sacudes las cadenas e intentas liberarte de la historia, del presente y maldices, maldices ferozmente a aquel que te dice que no puedes ser” (Rivas 2017: 0:29-0:44).

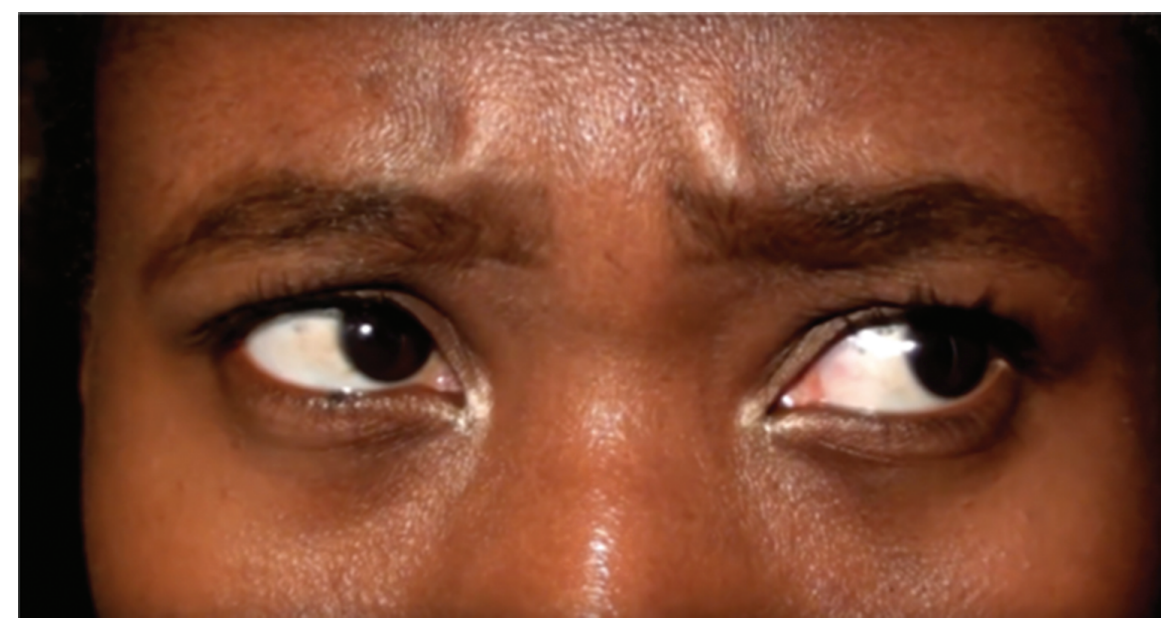

Ilustración 8: Tercera etapa (Rivas 2017: 0:40).

A diferencia de la propuesta de Pelo Bueno, Afro Power reconoce haber pertenecido a los vulnerables que han puesto de su parte por encajar en la sociedad blanqueada y que han llorado de dolor y de rabia al darse cuenta de que la adaptación supone negar su fisionomía, su cuerpo y su pelo, los cuales no en vano son, como afirma Mercer, los marcadores más tangibles de la negritud (cf. Mercer 1987: 35). Pelo Bueno otorgaba únicamente cualidades pasivas y negativas al llanto como expresión de la emoción del temor. Afro Power presenta el temor y la vulnerabilidad como cualidad activa, como fuente de energía a par- 
tir de la cual actuar, gritar, sacudirse la emoción hacia fuera y como punto de inflexión necesario en un proceso emocional que desemboca en su reconstitución identitaria. Esta reconstitución de la identidad alrededor de la "raza" como signo (cf. Segato 2010: 137) la realiza la voz en off a través de un acto de habla en el que establece su alteridad constitutiva "maldiciendo ferozmente" a quien le negaba su identidad negra, la sociedad mayorizada blanqueada.

El sonido de cuerno y la pregunta: “¿Quién soy yo?” (Rivas 2017: 0:45), mientras se intercalan fotos de Rivas de antes de iniciar la transición al pelo natural, marcan el comienzo de la segunda etapa en la narrativa coming of age de Afro Power. Asimismo, indican un punto de inflexión o el desplazamiento hacia el renacimiento de la identidad de la protagonista, anunciada por los elementos audiovisuales típicos de las películas de ciencia ficción que se mencionaban al principio del capítulo y del acto de habla de maldecir que acabamos de presentar. Este renacimiento se materializa claramente con la aparición de la protagonista llevando el pelo afro. Los planos de los árboles mostrados en contrapicado que abren esta segunda parte, el resto de planos que le siguen del cielo y de otros elementos de la naturaleza y la luminosidad contrastan con el espacio cerrado y lúgubre en el que se mostraba a la protagonista en la fase identitaria y emocional anterior. Además, estos planos sirven para expresar, siguiendo la interpretación convencional de los espacios abiertos y cerrados, la libertad adquirida por la protagonista en su re-constitución identitaria. En sus propias palabras, se propone:

iniciar de cero, cuando Oya el Osha de los antepasados y la falta de memoria me mostró los siglos de toda la historia que había olvidado y ya no pude retroceder. Ya me había descubierto y sabía que desde ese momento solo podía ver y sentirme, altiva, orgullosa por lo que era y lo que había elegido ser. (Rivas 2017: 0:52-1:09)

Rivas alude a Oya, una Osha, es decir, una divinidad femenina de la muerte y de los vientos huracanados, propia de la religión Yoruba, practicada por afrodescendientes en varias regiones del Caribe. De este modo, coindice con Pelo Bueno en su entendimiento transnacional de la afrodescendencia a través de la referencia explícita a elementos culturales compartidos más allá de las fronteras nacionales. Rivas afirma que fue esta divinidad la que le recordó la historia de la opresión afrodescendiente, con lo que se hace hincapié en el elemento unificador de la comunidad, al que también hacía referencia Pelo Bueno: la experiencia de la discriminación con su origen en la esclavitud. Rivas reconoce que esta historia la había olvidado en su adaptación a la sociedad mayorizada y que accedió a reconocer su corporalidad después de una fase previa de decolonización del conocimiento sobre el colectivo en el que se integra ahora. Es decir, para Rivas la decolonización de la mente desencadenó irreversiblemente 
la decolonización del cuerpo, precisamente los dos elementos por los que lucha el activismo estético, como se definía al inicio de este artículo.

Este hito provoca un desplazamiento en su dispositivo emocional hacia el emotive del orgullo: en sus palabras ya "solo podía ver y sentirme altiva, orgullosa por lo que era y lo que había elegido ser” (Rivas 2017: 1:04-1:09). La sensación de altivez se refuerza visualmente a través del ángulo adoptado por la cámara en contrapicado, o en angulación oblicua superior, que tiene la función convencional de transmitir la superioridad del personaje y le permite, además, a la protagonista mirar desde arriba, gesto típico de la altivez (Ilustración 9). Al igual que en el vídeo de Pelo bueno, el orgullo se expresa acústicamente a través de la apropiación de los tambores, marcador de la negritud cultural por la que Rivas se decanta en una aproximación constructivista de la identidad, por "lo que había elegido ser” (Rivas 2017: 1:09).

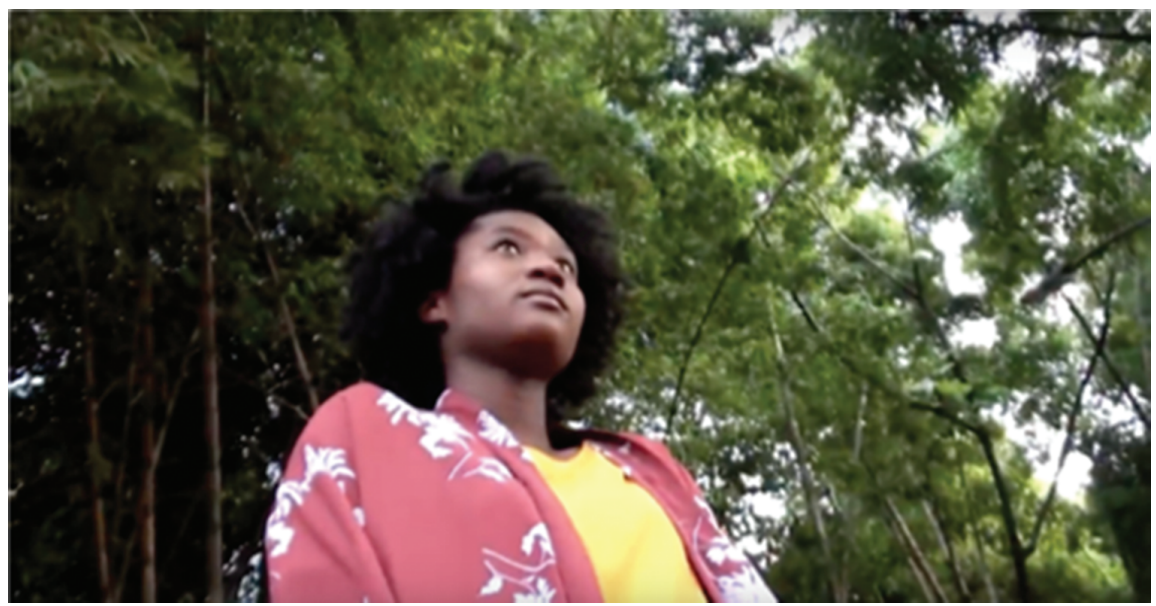

Ilustración 9: La llegada al orgullo. (Rivas 2017: 0:54)

Como se hiciera en Pelo bueno, Afro Power también se refiere a las mujeres que no abrazan la estética del pelo natural por diferentes motivos, pero ni el texto, ni los signos audiovisuales rezuman antagonismo hacia ellas. Es más, se muestra incluso comprensión hacia las que no se atreven o se echan atrás: "llevar el cabello natural, o, mejor dicho, reconocerse, reafirmarse, ser diferente o como lo quieran llamar es una decisión difícil” (Rivas 2017: 1:22-1:30). Con la conjunción disyuntiva $o$ se introduce una oración coordinada que añade la definición de lo que significa llevar el pelo natural. Esta opción se concibe más allá de lo meramente estético, como parte de un reconocimiento de la belleza propia no blanqueada y de la reafirmación cultural afrodescendiente, lo que, arguye Rivas, no es nada fácil. Asimismo, 
explica dónde radica la mayor dificultad de la decisión: esta es "quizá más difícil de sostener cuando parece que todo el mundo te señala y las miradas fijas parecen inquisidoras” (Rivas 2017: 1:29-1:34). El efecto de la mirada objetivadora y sojuzgadora de la (hetero)normatividad blanqueada es tan fuerte que, afirma, puede llegar a desestabilizar o incluso llegar a volcar la barca del orgullo por el que tanto se ha luchado hacia su opuesto constitutivo, la vergüenza.

En este punto se observa una diferencia con la concepción del orgullo en el vídeo de presentación de Pelo bueno. Con el poema de Campbell Barr, no solo se silencia el proceso emocional con el que se lidia hasta llegar a esta emoción, sino que esta se presenta como estable y estanca. ${ }^{18}$ En contraste, Rivas reconoce indirectamente la fragilidad y porosidad del orgullo. La vergüenza que se filtra en los poros del orgullo en este vídeo no se nombra en ninguno de los clips pero se intuye escondida, acechante. Sin embargo, como ya se indicaba con anterioridad, del clip de Rivas se deduce un entendimiento de la vulnerabilidad y de la vergüenza que difiere del de Tatis. Si esta última definía la vulnerabilidad y otras emociones relacionadas con ella de manera oposicional y un tanto dicotómica a la resistencia y a la agencia, la primera la articula como constituyente, no solo en el proceso emocional que lleva a la asunción del orgullo de ser "negra", sino también una vez alcanzada dicha emoción. De este modo, sigue la re-conceptualización propuesta por Butler, Gambetti y Sabsay de la vulnerabilidad como componente, fuente y fuerza engendradora de toda resistencia política de grupos minorizados y/o estigmatizados, y, por lo tanto, no como antónimo de la resistencia, y como tal, lugar de inacción, victimización y falta de agencia (cf. Butler / Gambetti / Sabsay 2016a y 2016b). Halperin, por su parte, en una comprensión de la vergüenza pareja a la propuesta por Butler, Gambetti y Sabsay, considera que el reconocimiento continuo de esta emoción es fundamental para evitar la conformidad del colectivo minorizado en el bienestar y que se olvide que el orgullo proviene del dolor, de la vergüenza y de su energía transformadora (cf. Halperin 2009: 44). ${ }^{19}$

En línea con lo expuesto, este tratamiento de la vulnerabilidad y de la vergüenza no impide a la protagonista de Afro Power terminar el vídeo animando a sus visitantes a comprobar, lo que de nuevo semantiza como definitorio de llevar el pelo natural, "la experiencia de sentirse libre, de ser capaz de decidir, de ir en contra de la corriente, de saberse, de amarse” (Rivas 2017: 1:37-1:45). Esta experiencia de libertad, de agencia en la toma de decisiones en contra de la sociedad mayorizada y de amor a una misma, comenta, es tan enriquecedora como inexpresable con palabras. Las

18 Esto es posible, en parte, gracias a las posibilidades que ofrece el género del texto que propone Rivera en contraposición a la lírica puesta en escena por Tatis.

19 Este entendimiento de la vulnerabilidad también se observa en Bost / Bruce / Manning 2019: 3. 
imágenes que cierran el vídeo compensan esta inexpresabilidad a la que hacía referencia Rivas y muestran a la protagonista sonriente, relajada, confiada, exhibiendo su cuerpo y su pelo, al igual que hiciera Pelo bueno. Rivas va un paso más allá y llega incluso a coquetear con la cámara (Ilustración 10 y 11). Por último, la luz del atardecer, que funciona como metáfora de la realización personal, ciega al espectador y cierra el vídeo (Ilustración 12).

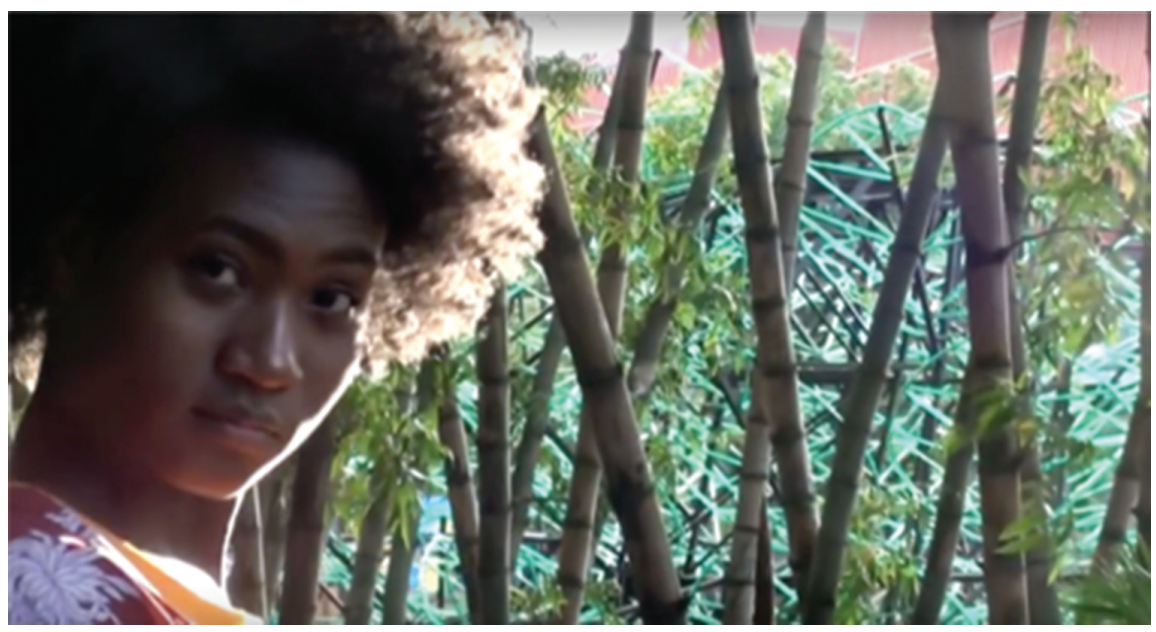

Ilustración 10: El orgullo. (Rivas 2017: 1:26)

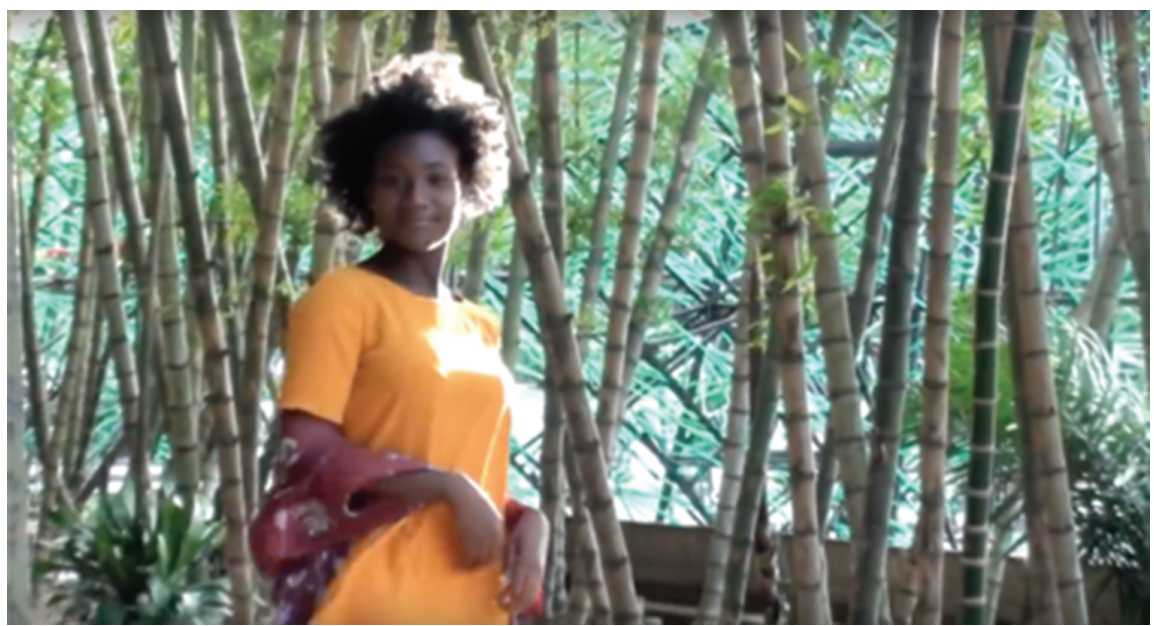

Ilustración 11: El bienestar. (Rivas 2017: 1:44) 


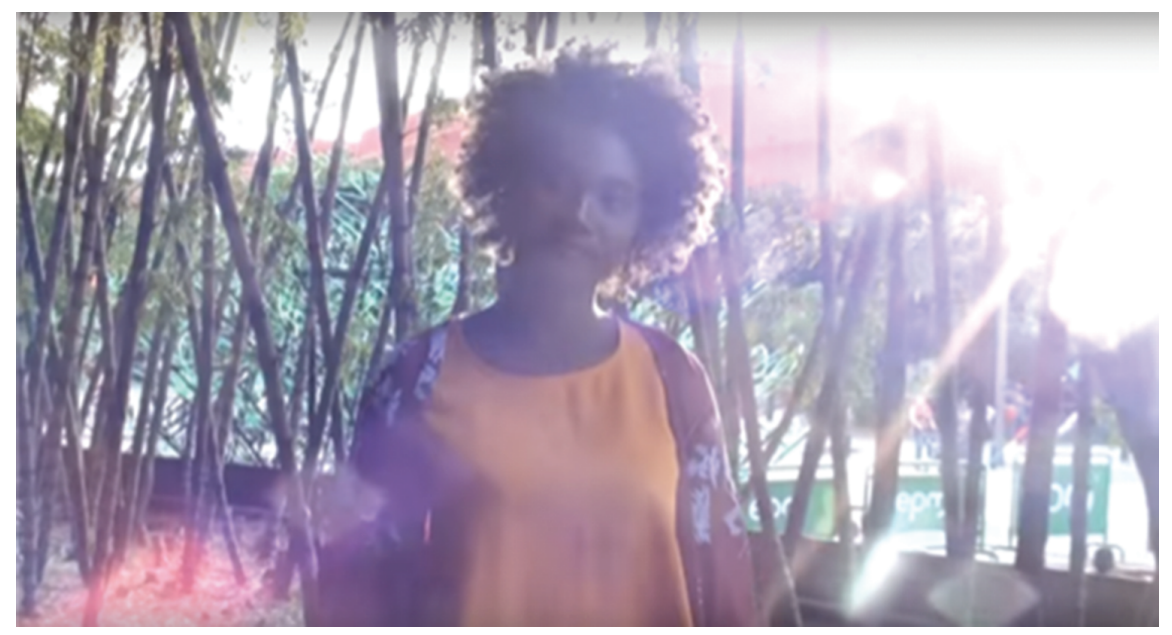

Ilustración 12: La realización personal. (Rivas 217: 1:32)

\section{Conclusión}

Este artículo ha mostrado cómo a pesar de los avances legislativos en Colombia desde finales del siglo pasado y del fuerte activismo afrodescendiente de las últimas décadas, este grupo demográfico sigue siendo un desplazado social, mediático y académico de la sociedad colombiana. Se ha demostrado que los afrocolombianos siguen sufriendo a día de hoy las consecuencias de la trata de esclavos y de los procesos de racialización de las personas africanas que se desencadenaron con la misma para justificar su empresa. La segregación racial de los afrodescendientes hacia la periferia del país desde principios del siglo XIX ha forjado verdaderas geografías de la pobreza en Colombia (cf. Lao-Montes 2009: 234; Rincón Becerra 2017: 2289). Al mismo tiempo esta segregación racial programada ha promovido la instauración de un imaginario racializado de la geografía de la nación que invisibiliza la diversidad de experiencias afrodescendientes en Colombia (cf. Wade 1997: 83; Zapata Cortés 2018: 25; Restrepo 2013: 51; Agudelo 2004: 174; Cunin 2004: 148). Asimismo, se ha argüido que las funciones pos-masivas (cf. Lemos 2010: 404) de las redes sociales han abierto nuevos canales de expresión y de interacción entre los afrocolombianos a través de los que pueden (re-)negociar lo que significa ser afrodescendiente (cf. Da Moita Lopes 2010: 398; Vergès 2017: 46; Sobande 2017: 657).

Tras una caracterización del género del vlog y de la plataforma de Youtube -una de las más visitadas en Colombia (cf. Chiquiza Nonsoque 2018)-, en este 
artículo se han analizado los vídeos de inicio de dos de las vloggers afrodescendientes practicantes del activismo estético más influyentes en Colombia. Se han examinado a partir del análisis multimodal del discurso (cf. Kress 2010) las estrategias comunes de Tatis y Rivas en la articulación de los emotives (cf. Reddy 2001) a través de los cuales expresan la unidad y, a la vez, la diversidad del colectivo afrodescendiente en el que articulan su identidad "negra”, entendida esta en ambos casos como signo (cf. Segato 2010). Los primeros planos, su superposición y las transiciones no jerárquicas refuerzan esta concepción diversa de la comunidad afro. Se ha observado que ambas se reapropian del sonido de los tambores o del cuerno para indicar el origen común de los afrodescendientes en su vertiente transnacional. La declamación de una poesía costarricense, la inserción de subtítulos en inglés y de referentes Yoruba demuestran la amplitud de la transnacionalidad que proponen los clips. El significante "historia" se usa en ambos casos para significar la riqueza del legado cultural de los antepasados y, al mismo tiempo, para referirse a la matriz de la racialización sufrida en el presente y sus raíces en la esclavitud.

Asimismo, se han explorado las diferentes aproximaciones que presentan las vloggeras a la expresión de las emociones en relación con la transición al pelo natural y con el cuidado del cuerpo afrodescendiente. Ambas señalan el orgullo y el bienestar como el resultado de dicho cuidado del cuerpo y de la mente a través del lenguaje verbal y de primeros planos centrados en mostrar la bella quinesia relajada y confiada de las mujeres. No obstante, el emotive del orgullo se articula de maneras diferentes en cada clip. La puesta en escena del poema "Rotundamente negra" de la costarricense Shirley Campbell Barr en el clip de Pelo bueno silencia el proceso emocional con el que se lidia hasta llegar a esta emoción, la cual se articula, además, como estable y estanca. De igual manera, se distancia explícitamente de cualquier expresión y/o reconocimiento de la vulnerabilidad. Los primeros planos del rostro de las mujeres con quinesia endurecida al hablar de los "no orgullosos" a los que se opone y las perífrasis terminativas "dejar de" para señalarlos revelan que en este clip la vulnerabilidad se concibe como antónima e incompatible con el activismo estético, además de engendradora de victimización, falta de agencia e inacción política.

Afro Power también constituye a su otro cuando "maldice ferozmente" a la sociedad mayorizada. No obstante, no incluye a los afrocolombianos que no han abrazado la estética afro en esa alteridad a la que se opone. De hecho, el clip se centra en mostrar el proceso emocional por el que -siguiendo la metáfora conceptual de Reddy- navega hasta llegar al orgullo. Para ello hace uso de convenciones narrativas y audiovisuales típicas de la ciencia ficción, como los latidos del corazón, el juego de luces, el uso de los espacios y los ojos abiertos y cerrados, para marcar el renacimiento identitario de Tatis. Esta reconoce, ade- 
más, la fragilidad y porosidad del orgullo y se muestra comprensiva con los efectos de la vergüenza, la emoción que acecha tras el orgullo en el sistema emocional. Afirma comprender la manera de actuar de los afrodescendientes (todavía) blanqueados, enseña fotos propias de su fase "no afro" y propone una reflexión sobre el proceso por el que se navega hasta llegar al orgullo a partir de su propia experiencia. La llegada -si bien nunca definitiva- a la emoción del orgullo se enfatiza audiovisualmente por el uso de planos en contrapicado y convenciones de significado del espacio abierto en un atardecer cálido con el que se cierra la narrativa coming of age. Si bien no se hace una reflexión racional sobre la vulnerabilidad en el clip, el entendimiento de la misma que se deduce del vídeo se acerca a la de estudios recientes sobre la misma. Estos estudios actualizan el potencial de la vulnerabilidad en la expresión política de la resistencia (cf. Butler / Gambetti / Sabsay 2016b) o la consideran fundamental para evitar la conformidad del colectivo en el bienestar (cf. Halperin 2009: 44). De esta manera, arguyen, se evita que el colectivo orgulloso e instalado en la autoestima se olvide de que la fuente inevitable de esta emoción es el dolor y la vergüenza sobre el aspecto físico $u$ otros rasgos de la identidad denostados por la sociedad mayorizada. Se recuerda, así, que es precisamente de estas emociones de donde surge la fuerza transformadora que conduce al otro extremo del espectro emocional, el orgullo.

\section{Bibliografía}

ACNUR = La Agencia de la ONU para los Refugiados (2019): Tendencias globales.

Desplazamiento forzado en 2018. <https://www.acnur.org/5d09c37c4.pdf> (3/02/2020).

Agudelo, Carlos Efrén (2004): “No todos vienen del río: construcción de identidades negras

urbanas y movilización política en Colombia”. En: Restrepo, Eduardo / Rojas, Axel (eds.):

Conflicto e (in)visibilidad. Retos en los estudios de la gente negra en Colombia. Popayán:

Editorial Universidad del Cauca, pp. 173-194.

Bost, Darius / Bruce, La Marr Jurelle / Manning, Brandon J. (2019): “Introduction, Black

Masculinities and the Matter of Vulnerability". En: The Black Scholar 49.2, pp. 1-10.

Butler, Judith (1990): Gender Trouble. Feminism and the Subversion of Identity. London / New York: Routledge.

Butler, Judith (1996): Excitable Speech: A Politics of the Performative. London / New York: Routledge.

Butler, Judith (2016): “Rethinking Vulnerability and Resistance”. En: Butler, Judith / Gambetti, Zeynep / Sabsay, Leticia (eds): Vulnerability in Resistance. Durham: Duke University Press, pp. 12-27.

Butler, Judith / Gambetti, Zeynep / Sabsay, Leticia (eds.) (2016a): Vulnerability in Resistance. Durham: Duke University Press. 
Butler, Judith / Gambetti, Zeynep / Sabsay, Leticia (2016b): “Introduction”. En: Butler, Judith / Zeynep Gambetti / Sabsay, Leticia (eds). Vulnerability in Resistance. Durham: Duke University Press, pp. 1-11.

Campbell Bar, Shirley (2006) [1994]: “Rotundamente negra”. En: Campbell Bar, Shirley: Rotundamente negra. San José: Ediciones Perro Azul Poesía, p. 89.

Chiquiza Nonsoque, Johan (2018): “Al día se ven 200 millones de videos de YouTube en Colombia”. En: La República. <https://www.larepublica.co/empresas/al-dia-se-ven-200millones-de-videos-de-youtube-en-colombia-2718418> (13/11/2019).

Cuevas, María-Fernanda (2018): “El proceso de la abolición de la esclavitud en la Nueva Granada (1780-1860). Tiempos y contratiempos de una transición significativa, entre la Revolución y la República”. En: Nuevo Mundo Mundos Nuevos. <https://doi.org/10. 4000/nuevomundo.72382>.

Cunin, Elisabeth (2004): “De la esclavitud al multiculturalismo: el antropólogo entre identidad rechazada e identidad instrumentalizada”. En: Restrepo, Eduardo / Rojas, Axel (eds.): Conflicto e (in)visibilidad. Retos en los estudios de la gente negra en Colombia. Popayán: Editorial Universidad del Cauca, pp. 147-156.

Da Moita Lopes, Luis Paulo (2010): “Os novos letramentos digitais como lugares de construção de ativismo político sobre sexualidade e gênero". En: Trabalhos em Linguística Aplicada 49.2, pp. 393-417.

DANE = Departamento Administrativo Nacional de Estadística (2018): “Indicadores básicos de tenencia y uso de Tecnologías de la Información y Comunicación -TIC en hogares y personas de 5 y más años de edad". En: Boletín técnico. <https://www.dane.gov.co/files/ investigaciones/boletines/tic/bol_tic_hogares_departamental_2018.pdf> (13/11/2019).

De Piero, José Luis (2014): “El vlog como género discursivo: algunos aportes para su definición”. En: Jornaleros. Revista científica de estudios literarios y lingüísticos 1, pp. 79-86.

Ferreira, Ricardo Alexino (2006): “Negro midiático: construção e desconstrução do afro-brasileiro na mídia impressa”. En: Revista USP 69, pp. 80-91.

Freire, Germán et al. (eds.) (2018): Afrodescendientes en Latinoamérica. Hacia un marco de inclusión. Washington: Banco Mundial.

Góngora Mera, Manuel / Vera Santos, Rocío / Costa, Sérgio (2019): Entre el Atlántico y el Pacífico Negro. Afrodescendencia y regímenes de desigualdad en Sudamérica. Madrid / Frankfurt a. M.: Iberoamericana / Vervuert.

Gruzinski, Serge (2004): Les quatre parties du monde. Histoire d'une mondialisation. Paris: Éditions La Martinière.

Halperin, David (2009): “Why Gay Shame Now?” En: Halperin, David / Trub, Valery (eds.): Gay Shame. Chicago: University of Chicago Press, pp. 41-48.

Jurado, Ángeles (2018). "Llevar el cabello afro natural es una forma de resistencia". En: El País. <https://elpais.com/elpais/2018/11/21/africa_no_es_un_pais/1542755805_ 331394.html> (13/11/2019).

Kress, Gunther (2010): Multimodality: A Social Semiotic Take on Contemporary Communication. London / New York: Routledge.

Lao-Montes, Agustín (2009): "Cartografías del campo político afrodescendiente en América Latina”. En: Universitas humanística 68, pp. 207-245.

Lemos, André (2010): "Post-Mass Media Functions, Locative Media, and Informational Territories: New Ways of Thinking About Territory, Place, and Mobility in Contemporary Society”. En: Space and Culture 13.4, pp. 403-420. 
Maldonado, Silvia (2011): Representaciones sociales en prácticas discursivas de la colonia. Tucumán: Universidad Nacional de Tucumán.

Marchant, Ivan (2018): “El estado del Social Media en América Latina”. En: ComScore. <https://www.comscore.com/lat/layout/set/popup/Request/Presentations/2017/Stateof-Social-Media-in-Latin-America? $\log 0=0 \& c=12$ ? utm_campaign=CONFIRMED_OPT_IN_ AUTO_RESPONDER_ALL\&utm_medium =email\&utm_source=comscore_elq_OPTIN_CONFIR MATION_CONTENT_ALL_AR> (13/11/2019).

Mbomío, Lucía (2018): “El activismo estético implica descolonizar también el cuerpo, no solo la mente”. En: Pikara online magazine. <https://www.pikaramagazine.com/2018/09/de siree-bela-lobedde-libro/> (13/11/2019).

Mercer, Kobena (1987): “Black hair/style politics”. En: New Formations 3, pp. 33-54.

Montoya Arango, Vladimir / García Sánchez, Andrés (2010): “‘iLos afro somos una diversidad!’ Identidades, representaciones y territorialidades entre jóvenes afrodescendientes de Medellín, Colombia”. En: Boletín de Antropología Universidad de Antioquía 24.41, pp. 44-64.

Movimiento Cimarrón Colombiano (2017): “Censo 2018: no a la minorización de la población afrodescendiente en Colombia”. En: Movimiento Cimarrón. <http://movimientocimarron. org/hagamonos-contar-bien-no-a-la-minorizacion-de-la-poblacion-afrodescendiente-encolombia/> (13/11/2019).

Navarrete, Lina (2016): “Colombia es el segundo país con mayor consumo de video online”. En: Comunidad Eme. <http://www.comunidademe.com/colombia-es-el-segundo-paiscon-mayor-consumo-de-video-online/i-2021/> (13/11/2019).

Reddy, William (2001): The Navigation of Feeling. A Framework for the History of Emotions. Cambridge / New York: Cambridge University Press.

Restrepo, Eduardo (2008): “Racismo y discriminación”. En: Rojas, Alex (coord.): Cátedra de Estudios Afrocolombianos. Aportes para Maestro. Popayán: Editorial Universidad del Cauca, pp. 192-204.

Restrepo, Eduardo (2013): “Articulaciones de negridad: políticas y tecnologías de la diferencia en Colombia”. En: Grimson, Alejandro / Bidaseca, Karina Andrea (eds.): Hegemonía cultural y políticas de la diferencia. Buenos Aires: Clacso, pp. 135-146.

Restrepo, Eduardo / Rojas, Axel (2004): Conflicto e (in)visibilidad. Retos en los estudios de la gente negra en Colombia. Popayán: Editorial Universidad del Cauca.

Rincón Becerra, Claudia Patricia (2017): “La población afrocolombiana, asilada, refugiada, exiliada en España una experiencia desde el ser negro/a”. En: Vicente Rabanaque, Teresa / García Hernadorena, María José / Vizcaino Estevan, Tono (eds.): Antropologías en transformación. Sentidos, compromisos y utopías: XIV Congreso de Antropología (València, 5-8/9/2017). València: Universitat de València, pp. 2287-2295.

Rivas, Yudis (2017): “Tres años natural: Mi experiencia. Três anos natural: reflexão SUBS”. En: Afro Power. <https://www.youtube.com/user/afropowerJY/featured> (13/11/2019).

Rivers, Nicola (2017): Postfeminism(s) and the Arrival of the Fourth Wave: Turning Tides. Cham: Palgrave Macmillan.

Rodríguez, Uriel (2018): “Más de 35.000 afrodescendientes serían víctimas de desplazamiento durante 2018". En: Bluradio. <https://www.bluradio.com/nacion/masde-35000-afrodescendientes-serian-victimas-de-desplazamiento-durante-2018-189826ie430> (03/02/2020). 
Segato, Rita (2010): “Raza es signo”. En: Mosquera-Lavé, Claudia / Laó-Montes, Agustín / Rodríguez Garavito, César (eds.): Debates sobre ciudadanía y políticas raciales en las Américas Negras. Cali: Universidad del Valle, pp. 555-579.

Shapiro, Sherry B. (2017): “Haunted by Meaning. Dance as Aesthetic Activism”. En: Karkou, Vicky / Oliver, Sue / Lycouris, Sophia (eds.): The Oxford Handbook of Dance and Wellbeing. New York: Oxford University Press, pp. 661-681.

Sobande, Francesca (2017): "Watching me watching you: Black Women in Britain on Youtube". En: European Journal of Cultural Studies 20.6, pp. 655-671.

Tatis, Cirle (2016): "Rotundamente negra”. En: Pelo bueno. <https://www.youtube.com/channel/ UCXyCp7Td0VyJUguvsLqjwww/featured> (13/11/2019).

Urrea Giraldo, Fernando / Rodríguez Sánchez, Diego Alejandro (2016): “Desafíos y perspectivas teóricas y metodologías comparativas. Importancia de un acercamiento cuantitativo sociodemográfico a la dimension étnico-racial en América Latina”. En: Rojas, Axel / Liberac Cardoso Simões Pires, Antônio / Dos Santos Gomes, Flávio (eds.): Território de gente negra: processos, transformações e adaptações. Ensaios sobre Colômbia e Brasil. Bahia: Editora UFBR.

Vergès, Françoise (2017): “Digital Africa”. En: Journal of the African Literature Association 11.1, pp. 45-49.

Wade, Peter (1997): Raza y etnicidad en Latinoamérica. Quito: Ediciones Abya-Yala.

Wade, Peter (2017): “Estudios afrodescendientes en Latinoamérica: racismo y mestizaje”. En: Tabula Rasa 27, pp. 23-44.

Zapata Cortés, Catalina (2018): Tejidos mediáticos de lo negro. Hacia una topografía racializada de la nación colombiana. Bogotá: Editorial Pontificia Universidad Javeriana. 
